\title{
Toxic metal and nicotine content of cigarettes sold in China, 2009 and 2012
}

\author{
Richard J O'Connor, ${ }^{1}$ Liane M Schneller, ${ }^{1}$ Rosalie V Caruso, ${ }^{1}$ W Edryd Stephens, ${ }^{2}$ \\ Qiang Li, ${ }^{3,4}$ Jiang Yuan, ${ }^{3}$ Geoffrey T Fong ${ }^{4,5,6}$
}

${ }^{1}$ Department of Health Behavior, Roswell Park Cancer Institute, Buffalo, New York, USA

${ }^{2}$ Department of Earth \& Environmental Sciences, University of St Andrews, Fife, UK

${ }^{3}$ Chinese Centers for Disease Control and Prevention, Beijing, China

${ }^{4}$ Department of Psychology, University of Waterloo, Waterloo, Ontario, Canada ${ }^{5}$ Ontario Institute for Cancer Research, Toronto, Ontario, Canada

${ }^{6}$ School of Public Health and Health Systems, University of Waterloo, Waterloo, Ontario, Canada

\section{Correspondence to} Dr Richard I O'Connor, Department of Health Behavior, Roswell Park Cancer Institute, Elm and Carlton Streets, Buffalo, NY 14263, USA; Richard.Oconnor@ roswellpark.org

Received 22 May 2014 Accepted 1 October 2014 Published Online First 21 October 2014

\begin{abstract}
Background Metals of primary health concern can accumulate in the tobacco plant and contribute to smokers' exposures to carcinogens, a significant cause of the millions of smoking-related deaths in China each year. These exposures are due to the smoker's addiction to nicotine.
\end{abstract}

Objective This study sought to explore toxic heavy metal and nicotine concentrations in the tobacco of Chinese cigarette brands purchased in 2009 and 2012, as well as its regional variation.

Methods Cigarette packs for this study were purchased from seven Chinese cities in 2009 and 2012, and 91 pairs of cigarettes were matched based on UPC for comparison. Ten cigarette sticks were randomly selected from each pack and tested using polarised energy dispersive X-ray fluorescence (XRF) for arsenic (As), cadmium $(\mathrm{Cd})$, chromium $(\mathrm{Cr})$, nickel $(\mathrm{Ni})$ and lead $(\mathrm{Pb})$ concentrations. Nicotine analysis was conducted following Coresta's Recommended Method N62. Data analysis was conducted using SPSS, encompassing descriptive statistics, correlations and generalised estimating equations to observe changes in brand varieties overtime.

Findings On average, from 2009 to 2012, As, Cd, $\mathrm{Cr}$ and $\mathrm{Pb}$ concentrations have decreased in Chinese tobacco. Of the seven cities where the cigarette brands were purchased, only four cities showed significant differences of the selected metals from 2009 to 2012. However, there was no significant change in the tobacco nicotine content from 2009 to 2012.

Conclusions Tobacco in Chinese cigarettes purchased in seven geographically disbursed cities contains consistently high levels of metals, including carcinogens like $\mathrm{Cd}$. One source may be the improper use of fertilisers. These numbers should be monitored more carefully and regulated by health officials.

\section{INTRODUCTION}

Cigarette smoking in China results in about 140 million deaths per year. ${ }^{1}$ These deaths can ultimately be traced to repeated toxicant exposures overtime, including nitrosamines, polycyclic aromatic hydrocarbons, volatile organic compounds and metals. $^{2}{ }^{3}$ Tobacco grown in soils with high metal concentrations (whether due to natural variation, fertilisers, atmospheric deposition or pollution) $)^{4}$ may have a higher metal content depending on uptake and retention by plants, which is controlled by various factors including soil $\mathrm{pH}^{5}{ }^{6}$ Metals of primary health concern with respect to tobacco include arsenic (As), cadmium (Cd), chromium $(\mathrm{Cr})$, nickel $(\mathrm{Ni})$ and lead $(\mathrm{Pb}) .^{7}$ Four of these (As, $\mathrm{Cd}, \mathrm{Cr}(\mathrm{VI})$ and $\mathrm{Ni}$ ) are known to be carcinogenic to humans. ${ }^{7} \mathrm{~Pb}$ is a class $2 \mathrm{~B}$ carcinogen which also affects the nervous system and the neurodevelopment in youth. ${ }^{8} 9$ As and $\mathrm{Cd}$ exposures are also associated with cardiovascular and renal toxicities, ${ }^{8} 9$ and may act as cocarcinogens. ${ }^{10-12} \mathrm{Cd}, \mathrm{Pb}$ and $\mathrm{Ni}$ accumulate in tissues and fluids after smoking, ${ }^{6}{ }^{13-16}$ and both active and passive smoking are major sources for $\mathrm{Cd}$ and $\mathrm{Pb}$ exposure in the US population. ${ }^{15-18}$ Prior research has shown that the tobacco grown in China shows elevated levels of $\mathrm{Pb}$ and $\mathrm{Cd}$ compared with tobacco grown elsewhere. ${ }^{19-21}$ In the current study, we examine the concentration of heavy metals in tobacco from a selected sample of 2009 and 2012 Chinese cigarettes to determine if any changes in tobacco metal content over various brands occurred during that time period, as well as to explore regional variations in cigarette metal content within China.

The repeated exposure to these metals can be accounted for by the smoker's addiction to the nicotine in the tobacco. Nicotine is synthesised by the tobacco plant during growth, and is the primary alkaloid in the leaf tissue, making up about $95 \%$ of the total alkaloid content. ${ }^{22-24}$ In most cigarettes, a tobacco rod will contain about $10-14 \mathrm{mg}$ of nicotine, but only about $1-1.5 \mathrm{mg}$ of that will actually be absorbed while smoking. There is some evidence that the amount of nitrogen supplied to the plant during growth impacts the tobacco plant's nicotine content. ${ }^{24} 25$ Nitrogen is naturally found in soil and is one of two primary nutrients in fertilisers. ${ }^{24}$ The use of fertilisers is mainly to yield the greatest amount of growth; however, their improper use can negatively affect the environment. ${ }^{24}$ The current study sought to examine levels of metals of health concern and nicotine in cigarette tobacco obtained on the Chinese market in 2009 and 2012.

\section{METHODS}

Cigarette packs analysed for this study were purchased by field workers from seven Chinese cities (Beijing, Changsha, Kunming, Shanghai, Shenyang, Guangzhou and Yinchuan) in 2009 and 2012 at three large retail stores in each city (total $n=2052$; 2009, $n=907 ;$ 2012, $n=1145$ ). Packs were shipped to the Tobacco Research Laboratory at Roswell Park Cancer Institute (RPCI), where they were catalogued and stored unopened at $-20^{\circ} \mathrm{C}$ until analysis. The physical and design characteristics of a selected 197 cigarette packs were tested in accordance with the International Organization for Standardization (ISO) 3402:1999 after being conditioned for a minimum of $48 \mathrm{~h}$ at $22 \pm 2.0^{\circ} \mathrm{C}$ and
Schneller LM, Caruso RV et al. Tob Control 2015;24 iv55-iv59. 
$60 \pm 2.0 \%$ relative humidity in an environmental chamber. From this larger set, 91 pairs of cigarettes were matched based on Universal Product Code (UPC) to compare the 2009 and 2012 data. Cigarette physical and design characteristics were assessed and are reported elsewhere. ${ }^{26}$ Ten cigarette sticks were then selected randomly from each pack, placed in polypropylene zip-top bags with code numbers, and sent to the University of St. Andrews, Scotland for quantitation of trace elements using polarised energy dispersive X-ray fluorescence (XRF). Tobacco extracted from each cigarette was dried for $48 \mathrm{~h}$, then pulverised to a powder in a Rocklabs bench top mill using a tungsten carbide pot. Pellets (6 g) were pressed from the powder under 20 tons pressure. The heavy metals and other trace elements $(\mathrm{Mg}$, Al, Si, P, Cl, S, K, Ca, Ti, Cr, Mn, Fe, Ni, Cu, Zn, As, Br, Rb, Sr, $\mathrm{Zr}, \mathrm{Nb}, \mathrm{Cd}, \mathrm{Sn}, \mathrm{Ba}, \mathrm{Pb}$ ) were analysed quantitatively using an Epsilon 5 XRF with a Gd X-ray tube. A more complete description of methods, including limits of detection, can be found in previously published papers. ${ }^{27}{ }^{28}$ The tobacco nicotine content was conducted in-house using gas chromatographic analysis with nitrogen-phosphorous detection, generally following CORESTA's Recommended Method N ${ }^{\circ} 62$ with methyl tertbutyl ether as the extraction solvent and quinoline as the internal standard. ${ }^{29}$ Duplicate samples were run for each brand.

Statistical analysis of data was conducted using Statistical Package for the Social Sciences V.21.0 (IBM; Armonk, New York, USA). The metals and average tobacco rod nicotine were characterised using descriptive statistics and analysed for correlations. Changes as a function of time were assessed within subjects using generalised estimating equations (normal distribution, log link function and exchangeable working correlation matrix except where otherwise specified). Intraclass correlations were used to determine the repeatability of the nicotine analyses, and these values were compared with those of Kentucky Reference cigarettes using a one-sample t test.

\section{RESULTS}

Figure 1 displays mean concentrations for $\mathrm{As}, \mathrm{Cd}, \mathrm{Cr}, \mathrm{Ni}$ and $\mathrm{Pb}$ in micrograms per gram cigarette tobacco. As and $\mathrm{Pb}$ concentrations showed a strong correlation (Pearson Correlation $=0.844$; $\mathrm{p}<0.001$ ), but levels of the other metals were not significantly intercorrelated.

In terms of change in metal concentration from 2009 to 2012, mean concentrations of As $(\mathrm{D}=-0.06 \mu \mathrm{g} / \mathrm{g}$ of tobacco; $\mathrm{t}(89)$ $=2.014, \mathrm{p}=0.047), \mathrm{Cr}(\mathrm{D}=-0.15 \mu \mathrm{g} / \mathrm{g}$ of tobacco; $\mathrm{t}(89)=2.002$, $\mathrm{p}=0.048)$ and $\mathrm{Pb}(\mathrm{D}=-0.45 \mu \mathrm{g} / \mathrm{g}$ of tobacco; $\mathrm{t}(89)=3.762$, $\mathrm{p}<0.001$ ) decreased on average (Figure 1). Figure 2 gives a depiction of selected brands' metal concentrations in both 2009 and 2012-2A shows the Cd levels and 2B shows the Pb levels. The Beijing brand seemed to have a great decrease in $\mathrm{Pb}$ and $\mathrm{Cd}$ from 2009 to 2012, while most of the other brands had only small changes in their metal concentrations between the 2 years, if any at all.

The measured nicotine content on duplicate samples was stable (intraclass correlation $=0.915, \mathrm{p}<0.001$ ). The change in average rod nicotine was found to be not statistically significant between 2009 and 2012 (2009: $\mathrm{n}=71, \mu=19.98 \mathrm{mg} / \mathrm{g}$ of tobacco; 2012: $\mathrm{n}=68, \mu=19.63 \mathrm{mg} / \mathrm{g}$ of tobacco). As a point of reference, we compared these averages with the tobacco rod nicotine content of 3R4F Kentucky Reference cigarettes $(20.5 \mathrm{mg} / \mathrm{g}$ of tobacco) and found them to be significantly lower $(p<0.001)$. We also found significant correlations between the tobacco rod nicotine content and metal concentrations, with the exception of $\mathrm{Cd}$ (Table 1). Higher rod nicotine was positively associated with $\mathrm{As}$ and $\mathrm{Pb}$ levels, but negatively associated with $\mathrm{Ni}$ and $\mathrm{Cr}$ levels. In Figure 3, the five cigarette brands with the highest and lowest tobacco nicotine content are shown with their respective concentrations in 2012.

\section{DISCUSSION}

The Chinese cigarettes examined in this study contained various heavy metals known to adversely impact health. The average As, $\mathrm{Cd}$ and $\mathrm{Pb}$ levels in Chinese cigarettes were substantially greater than the range of the means found in the Americas. ${ }^{30-33}$ On the other hand, the $\mathrm{Cr}$ and $\mathrm{Ni}$ average concentrations appeared to be below that of the range of means. Broadly, the levels seen here for each metal are similar to those previously reported for cigarettes purchased in 2005/2006 and 2007 by O'Connor and colleagues. For comparison, O'Connor and colleagues performed a similar analysis on Chinese cigarette brands purchased in 2005-2006 and 2007 and found that the tested brands averaged $0.78 \mu \mathrm{g} / \mathrm{g}$ As (range 0.3-3.3), 3.24 $\mathrm{gg}$ gd (range 2.0-5.4), $0.55 \mu \mathrm{g} / \mathrm{g} \mathrm{Cr}$ (range $0.0-1.0$ ) and $2.54 \mu \mathrm{g} / \mathrm{g} \mathrm{Pb}$ (range 1.2-6.5). ${ }^{19}$ The levels reported here for $\mathrm{Cd}, \mathrm{Ni}$ and $\mathrm{Pb}$ are comparable to those in a prior report by our research group, while the As concentrations were notably lower.

These results highlight the sustained exposure among Chinese smokers to high levels of toxic metals. The high levels of $\mathrm{Cd}$ and $\mathrm{Pb}$ in Chinese cigarettes can be potentially problematic, given China's high smoking prevalence and per capita consumption, as a significant fraction of $\mathrm{Cd}$ and $\mathrm{Pb}$ transfers directly into smoke and is correlated with smoking intensity. Furthermore, $\mathrm{Cd}$ has a biological half-life of one to four decades and minimal

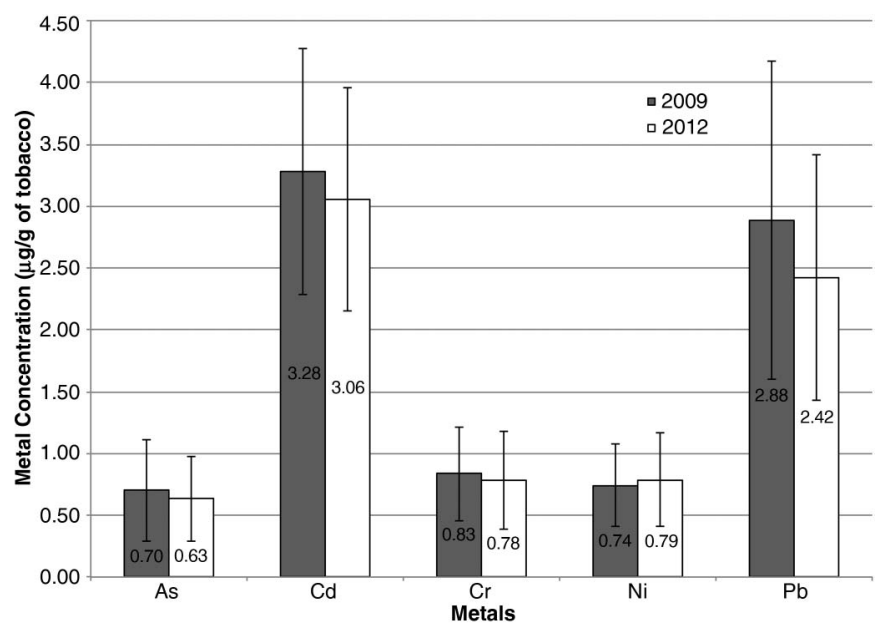

Figure 1 Mean concentrations ( $\mathrm{mg} / \mathrm{g}$ tobacco) of metals in cigarette tobacco, 2009 and 2012. 
Figure 2 (A) Concentration of $\mathrm{Cd}$ in selected cigarette brands, 2009 and 2012. (B) Concentration of $\mathrm{Pb}$ in selected cigarette brands, 2009 and 2012.
A

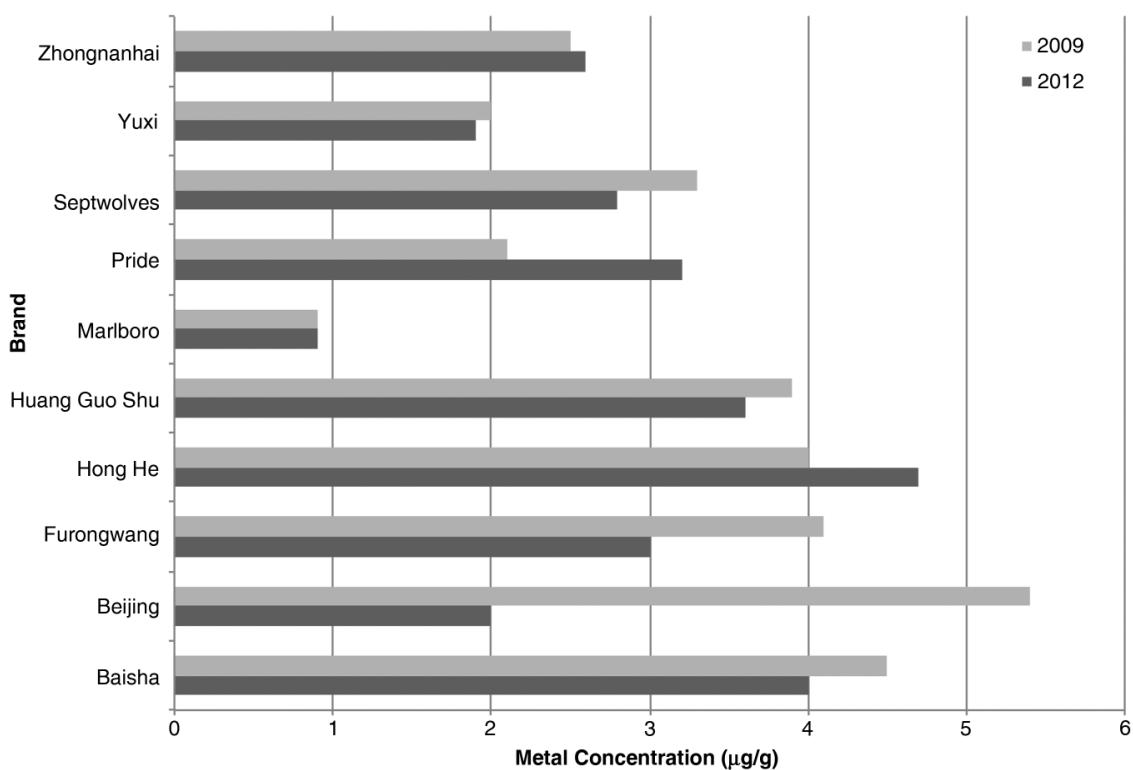

B

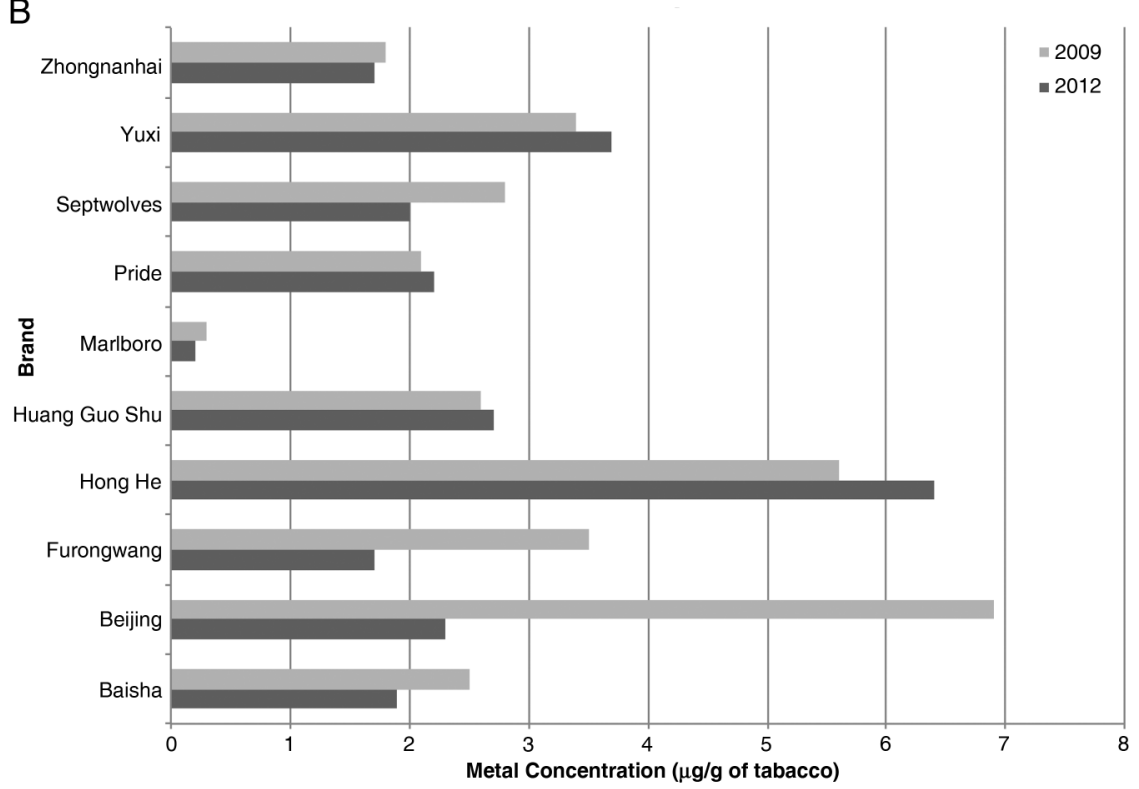

Table 1 Spearman correlation of average tobacco rod nicotine, and the primary metals of interest

\begin{tabular}{lcccccc}
\hline & $\begin{array}{l}\text { Average } \\
\text { rod } \\
\text { nicotine }\end{array}$ & As & Cd & Cr & Ni & Pb \\
\hline $\begin{array}{l}\text { Average } \\
\text { rod }\end{array}$ & 1.00 & $0.410^{*}$ & -0.024 & $-0.223^{*}$ & $-0.310^{*}$ & $0.322^{*}$ \\
nicotine & & & & & & \\
As & $0.410^{*}$ & 1.00 & $0.182 \dagger$ & $-0.255^{*}$ & $-0.313^{*}$ & $0.801^{*}$ \\
Cd & -0.024 & $0.182 \dagger$ & 1.00 & $-0.221^{*}$ & 0.122 & $0.289^{*}$ \\
Cr & $-0.223^{*}$ & $-0.255^{*}$ & $-0.221^{*}$ & 1.00 & $0.248^{*}$ & $-0.222^{*}$ \\
$\mathrm{Ni}$ & $-0.310^{*}$ & $-0.313^{*}$ & 0.122 & $0.248^{*}$ & 1.00 & $-0.312^{*}$ \\
$\mathrm{~Pb}$ & $0.322^{*}$ & $0.801^{*}$ & $0.289^{*}$ & $-0.222^{*}$ & $-0.312^{*}$ & 1.00 \\
\hline *Correlation is significant at the 0.01 level (two tailed). & & \\
tCorrelation is significant at the 0.05 level (two tailed). & &
\end{tabular}

excretion through the urinary tract, indicating that the body likely experiences long-term exposures. ${ }^{12}$ Metal contamination of agricultural products due to environmental pollution is a broader public health concern in China, particularly for foodstuffs, and recent reports have highlighted high levels of metals in vegetables, rice and fish. ${ }^{34-36}$ So Chinese smokers may be adding an additional metal burden to existing exposures.

Lastly, nicotine, the addictive component of tobacco, is thought to be affected by the plant's supply of nitrogen throughout growth. ${ }^{25}$ Given that fertilisers are intended to provide nitrogen as well as being a potential source of heavy metal contaminations, the use of fertilisers on tobacco crops may explain the observed correlation between the tobacco rod nicotine and metal content. ${ }^{24}$ Therefore, the regulation of fertiliser use may act as a means to decrease the amount of heavy metals found within the Chinese tobacco.

We note several limitations of this study. First, we do not have the ability to track the tobacco from growth to sale, although we do know that most of the tobacco grown in China is used 
Figure 3 Change in the nicotine concentration of selected cigarette brands, 2009 and 2012.

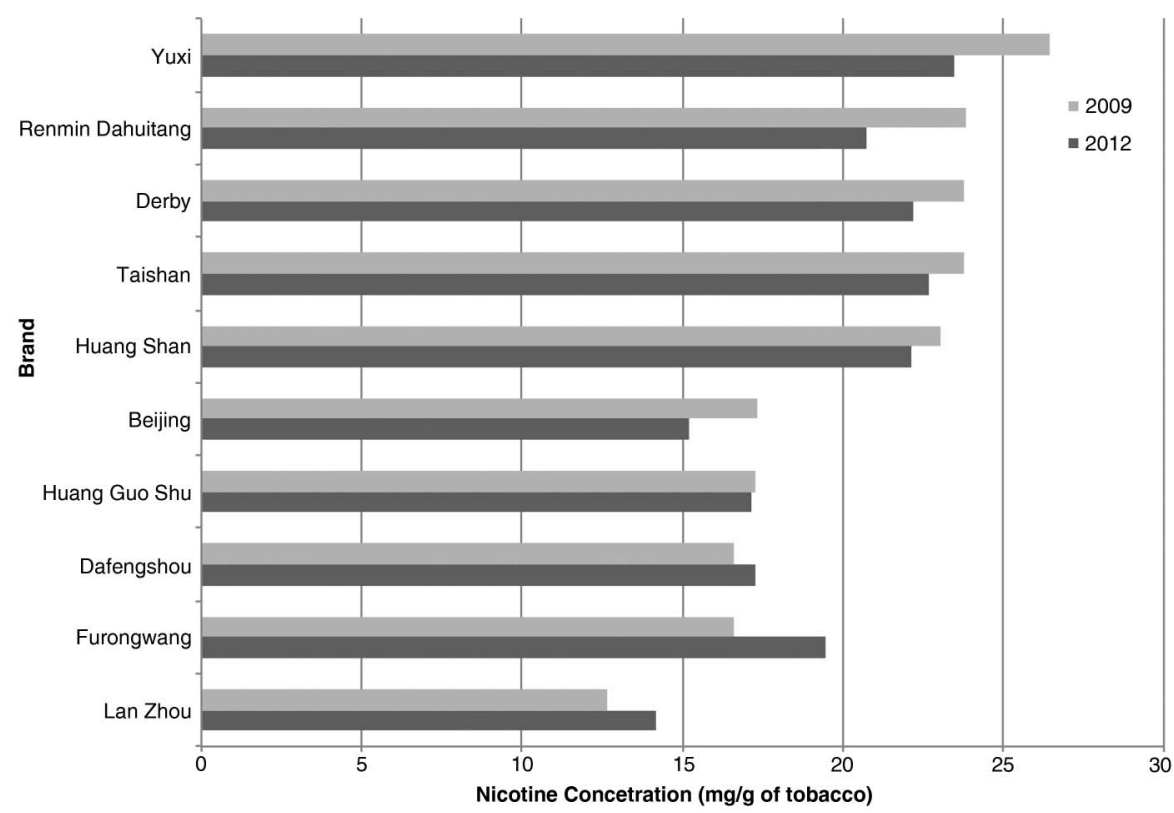

domestically, and we know in which cities the cigarettes produced and sold in China were purchased.However, we do not know where in China the tobacco was grown. Second, we have measured only the tobacco concentration of metals, not the smoke levels. The transfer rates differ for each metal and can range from $1 \%$ to $30 \%$, depending on a number of product and use factors. ${ }^{5}$ Also, we did not explore exposure biomarkers and therefore cannot specifically estimate the health effects caused by the metals in cigarette smoke. Lastly, owing to the lack of availability of additional cigarette sticks because of prior analyses, we were not able to analyse all cigarette pairs for nicotine content.

It is notable that TobReg, the WHO's expert panel on tobacco regulation, has recommended that "regulatory authorities ... consider requiring manufacturers to test cured tobacco purchased from each new agricultural source for levels of arsenic, cadmium, lead and nickel". ${ }^{37}$ Health officials and regulators in China should develop systems to monitor tobacco metal content and consider establishing upper limits on levels in tobacco as part of a broader effort to mitigate metal contamination of agricultural products throughout China. This should include an in-depth study of the primary sources (e.g. fertilisers, air pollution) of metal enrichment in Chinese tobacco. Precluding trade in tobacco and tobacco products with high toxic metal content could eventually have a positive impact on public health.

\section{What this paper adds}

- Many heavy metals are known carcinogens and exposure via smoking has been identified as a cause of death in smokers. These metals are absorbed through the soil from which the tobacco is grown, and are higher in cigarettes made from tobacco grown in China.

-We found that levels of toxic metals remain high in Chinese cigarettes. These concentrations should be regulated for the benefit of public health.

Acknowledgements The authors thank the China CDC staff and fieldworkers in each city for their assistance with data collection.
Contributors RJO, WES and GTF conceived the study. LMS and RVC led the data analysis. QL and JY contributed to data collection. All authors contributed to data interpretation and manuscript preparation.

Funding The ITC China Project was supported by grants from the US National Cancer Institute (R01 CA125116 and P01 CA138389), the Roswell Park Transdisciplinary Tobacco Use Research Center (P50 CA111236), the Robert Wood Johnson Foundation (045734); the Canadian Institutes of Health Research (57897, 79551 and 115016), and the Chinese Center for Disease Control and Prevention. Additional support was provided to Geoffrey T Fong from a Senior Investigator Award from the Ontario Institute for Cancer Research and a Prevention Scientist Award from the Canadian Cancer Society Research Institute.

Competing interests None declared.

Provenance and peer review Not commissioned; externally peer reviewed.

Data sharing statement Data are available from the first author on request.

\section{REFERENCES}

1 Global Adult Tobacco Survey: China. Global Tobacco Surveillance System. 2010. http://www.who.int/tobacco/surveillance/en_tfi_china_gats_factsheet_2010.pdf (accessed 9 Jan 2014).

2 Talhout R, Schulz T, Florek E, et al. Hazardous compounds in tobacco smoke. Int J Environ Res Public Health 2011;8:613-28.

3 U.S. Department of Health and Human Services. How tobacco smoke causes disease: the biology and behavioral basis for smoking-attributable disease: a report of the surgeon general. Atlanta, GA: US Department of Health and Human Services, Centers for Disease Control and Prevention, National Center for Chronic Disease Prevention and Health Promotion, Office on Smoking and Health, 2010. http://www.ncbi.nlm.nih.gov/books/NBK53021/ (accessed 27 Jan 2014).

4 Cobb GP, Sands K, Waters M, et al. Accumulation of heavy metals by vegetables grown in mine wastes. Environ Toxicol Chem 2000;19:600-7.

5 Rodgman A, Perfetti TA. The chemical components of tobacco and tobacco smoke. Boca Raton: CRC Press, 2009.

6 Pappas RS. Toxic elements in tobacco and in cigarette smoke: inflammation and sensitization. Metallomics 2011;3:1181-98.

7 IARC Monographs on the Evaluation of Carcinogenic Risks to Humans. Tobacco Smoke and involuntary smoking. IARC Monogr Eval Carcinog Risks Hum 2004;83:1-1438. World Health Organization.

8 Dorne JL, Kad GE, Bordajandi LR, et al. Human risk assessment of heavy metals: Principles and applications. Met lons Life Sci 2011;8:27-60.

9 Gidlow DA. Lead toxicity. Occup Med (Lond) 2004;54:76-81.

10 Delahunt B, Bethwaite JNN. Occupational risk for renal cell carcinoma. Br J Urol 1997;75:578.

11 Boffetta P. Involuntary smoking and lung cancer. Scand J Work Environ Health 2002;28:30.

12 Khlifi R, Olmedo P, Gil F, et al. Arsenic, cadmium, chromium, and nickel in cancerous and healthy tissues from patients with head and neck cancer. Sci Total Environ 2013;452-453:58-67.

13 Stojanović D, Nikić D, Lazarević K. The level of nickel in smoker's blood and urine. Cent Eur J Public Health 2004;12:187-9. 
14 Galazyn-Sidorczuk M, Brzóska MM, Moniuszko-Jakoniuk J. Estimation of Polish cigarettes contamination with cadmium and lead, and exposure to these metals via smoking. Environ Monit Assess 2008;137:481-93.

15 Richter PA, Bishop EE, Wang J, et al. Tobacco smoke exposure and levels of urinary metals in the U.S. youth and adult population: the National Health and Nutrition Examination Survey (NHANES) 1999-2004. Int J Environ Res Public Health 2009;6:1930-46.

16 Tellez-Plaza M, Navas-Acien A, Caldwell KL, et al. Reduction in cadmium exposure in the United States population, 1988-2008: the contribution of declining smoking rates. Environ. Health Perspect 2012;120:204-9.

17 Marano KM, Naufal ZS, Kathman SJ, et al. Cadmium exposure and tobacco consumption: Biomarkers and risk assessment. Regul Toxicol Pharmacol 2012;64:243-52.

18 Serdar MA, Akin BS, Razi C, et al. The correlation between smoking status of family members and concentrations of toxic trace elements in the hair of children. Biol Trace Elem Res 2012;148:11-17.

19 O'Connor RJ, Li Q, Stephens WE, et al. Cigarettes sold in China: design, emissions and metals. Tob Control 2010;19(Suppl 2):i47-53.

20 Stephens WE, Calder A, Newton J. Source and health implications of high toxic metal concentrations in illicit tobacco products. Environ Sci Technol 2005;39:479-88.

21 Pappas RS, Polzin GM, Watson CH, et al. Cadmium, lead, and thallium in smoke particulate from counterfeit cigarettes compared to authentic US brands. Food Chem Toxicol 2007:45:202-9.

22 Wang $\mathrm{P}$, Liang Z, Zeng J, et al. Generation of the tobacco lines with widely different reduction in nicotine levels via RNA silencing approaches. J Biosci 2008;33:177-84.

23 Benowitz NL, Hukkanen J, Peyton J. Nicotine chemistry, metabolism, kinetics and biomarkers. Handb Exp Pharmacol 2009;192:29-60.

24 Davies S, Reed M, O'Brien S. Vermont Legislative Research Shop. The University of Vermont, 2001. http://www.uvm.edu/ vlrs/doc/lawnfert.htm (accessed 22 May 2014).

25 Wang SS, Shi QM, Li WQ, et al. Nicotine concentration in leaves of flue-cured tobacco plants as affected by removal of the shoot apex and lateral buds. J Integr Plant Biol 2008;50:958-64.
26 Schneller LM, Zwierzchowski BA, Caruso RV, et al. Changes in tar yields and cigarette design in samples of Chinese cigarettes, 2009-2012. Under Review, 2013.

27 Stephens WE, Calder A. Analysis of non-organic elements in plant foliage using polarized X-ray fluorescence spectrometry. Analytic Chimica Acta 2004;527:89-96

28 Caruso RV, O'Connor RJ, Stephens WE, et al. Toxic Metal Concentrations in Cigarettes Obtained from the U.S. Smokers in 2009: Results from the International Control (ITC) United States Survey Cohort. Int I Environ Res Public Health 2013;10.

29 Cooperation Centre for Scientific Research Relative to Tobacco. Determination of Nicotine in Tobacco and Tobacco Products by Gas Chromatographic Analysis. Coresta Recommended Method N62. 2005. http://www.coresta.org/ Recommended_Methods/CRM_62.pdf (accessed 22 May 2014).

30 Fresquez MR, Pappas RS, Watson CH. Establishment of toxic metal reference range in tobacco from US cigarettes. J Anal Toxicol 2013;37:298-304.

31 Caruso RV, O'Connor RJ. Cigarette design features in low-, middle-, and high-income countries. Public Health 2012;2012:269576.

32 O'Connor RJ, Wilkins KJ, Caruso RV, et al. Cigarette characteristics and emission variations across high-, middle-, and low-income countries. Public Health 2010;124:667-74.

33 Viana GF, Garcia KS, Menezes-Filho JA. Assessment of carcinogenic heavy metals in Brazilian cigarettes. Environ Monit Assess 2011;181:255-65.

34 Buckley C. Rice Tainted With Cadmium Is Discovered in Southern China. The New York Times. 2013. http://www.nytimes.com/2013/05/22/world/asia/cadmiumtainted-rice-discovered-in-southern-china.html?_r=1\& (assessed 29 Jan 2014).

35 Zhao Q, Wang Y, Cao Y, et al. Potential health risks of heavy metals in cultivated topsoil and grain, including correlations with human primary liver, lung and gastric cancer in Anhui province, Eastern China. Sci Total Environ 2014:470-471:340-7.

$36 \mathrm{Cao} \mathrm{H,} \mathrm{Chen} \mathrm{J,} \mathrm{Zhang} \mathrm{J,} \mathrm{et} \mathrm{al.} \mathrm{Heavy} \mathrm{metals} \mathrm{in} \mathrm{rice} \mathrm{and} \mathrm{garden} \mathrm{vegetables} \mathrm{and}$ their potential health risks to inhabitants in the vicinity of an industrial zone in Jiangsu, China. J Environ Sci (China) 2010;22:1792-9.

37 WHO. Report on the scientific basis of tobacco product regulation : fourth report of a WHO study group. WHO study group on tobacco product regulation (WHO Technical Report Series). Geneva: World Health Organisation, 2012:83. 